\title{
BIOESTIMULANTE NA PROMOÇÃO DA BROTAÇÃO EM ESTACAS DE RAIZ DE AMOREIRA-PRETA ${ }^{1}$
}

\author{
JOÃO PAULO TADEU DIAS ${ }^{2}, \mathrm{KEIKO} \mathrm{TAKAHASHI}^{2}$, \\ JAIME DUARTE FILHO ${ }^{3}$, ELIZABETH ORIKA ONO ${ }^{4}$
}

RESUMO- Este trabalho objetivou verificar o efeito do bioestimulante Promalin ${ }^{\circledR}$ na promoção da brotação em estacas radiciais de amoreira-preta (Rubus spp.) cv. Brazos. O experimento foi conduzido de janeiro a março de 2010, sendo o delineamento inteiramente casualizado, com cinco concentrações de bioestimulante, na forma de solução: T1 $=0 \mathrm{mg} \mathrm{L}^{-1}$; T2= $10 \mathrm{mg} \mathrm{L}^{-1}$; T3= $20 \mathrm{mg} \mathrm{L}^{-1}$; T4= $40 \mathrm{mg} \mathrm{L}^{-1}$, e T5= $80 \mathrm{mg} \mathrm{L}^{-1}$, sendo as estacas radiciais mergulhadas nessas soluções durante 12 horas, em sete repetições com dez estacas cada. Após 75 dias, foram avaliadas: a emergência de brotos, o número de estacas brotadas, número de brotos, número de folhas, comprimento da haste principal e porcentagem de sobrevivência das brotações, além da análise de carboidratos solúveis. Ocorreu evolução gradativa ao longo do tempo na emergência das brotações, iniciando em aproximadamente sete dias após o plantio. As maiores concentrações de Promalin $®$ inibiram a brotação em estacas de raiz, e as características de desenvolvimento dessas brotações foram alteradas, sendo os melhores resultados alcançados sem a aplicação dos reguladores vegetais.

termos para indexação: Rubus spp., multiplicação, pequenos frutos, regulador vegetal.

\section{BIOSTIMULANT IN PROMOTING THE SPROUTING IN ROOT CUTTINGS OF BLACKBERRY}

\begin{abstract}
This study aimed to evaluate the effect of biostimulante Promalin ${ }^{\circledR}$ promoting sprouting in root cuttings of blackberry (Rubus spp.) cv. Brazos. The experiment was conducted from January to March 2010, with a completely randomized design with five concentrations of biostimulant, as solution: $\mathrm{T} 1=0 \mathrm{~m}$ $\mathrm{g} \mathrm{L}^{-1}, \mathrm{~T} 2=10 \mathrm{mg} \mathrm{L}^{-1}, \mathrm{~T} 3=20 \mathrm{mg} \mathrm{L}^{-1}, \mathrm{~T} 4=40 \mathrm{mg} \mathrm{L}^{-1}$ and $\mathrm{T} 5=80 \mathrm{mg} \mathrm{L}^{-1}$ with the root cuttings dipped in these solutions for 12 hours and seven replications, and the plot compose by ten root cuttings. After 75 days were examined: the emergence of shoots, number of sprouting, shoot number, leaf number, length of main stem and survival percentage of the shoots, besides the analysis of soluble carbohydrates. Gradual evolution has occurred over time in the emergence of the shoots, beginning in approximately seven days after planting. The

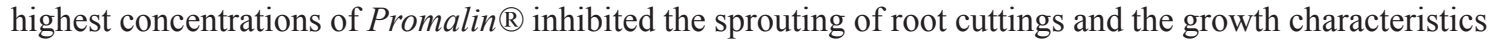
of these shoots, the best results were achieved without the application of the product.
\end{abstract}

Index terms: Rubus spp., multiplication, small fruits, plant growth regulator.

\section{INTRODUÇÃO}

A amoreira-preta (Rubus spp.) é uma espécie promissora para o cultivo e comercialização, podendo ser utilizada para consumo in natura e no fabrico de geleia e polpa. No Brasil, apesar de seu potencial, não apresenta produção significativa, o cultivo se destaca nos estados das regiões Sul e Sudeste.

No País, estima-se uma área cultivada com amoreira-preta de aproximadamente 250 hectares (RASEIRA, 2004). O Estado de São Paulo apresentou, na safra de 2007/2008, 213,47 hectares planta- dos, com 586.179 plantas, apresentando o município de Tarumã a maior área plantada (24,20 hectares), seguido pelos municípios de Duartina, Itatinga e Pariqueraçu (CATI, 2010).

A produção de mudas de amoreira-preta dáse, principalmente, por propagação assexuada, com o uso de estacas radiciais, rebentos (brotos), estacas herbáceas e lenhosas (JENNINGS; NCNICOL, 1991 apud VILLA et al., 2006). No entanto, o método tradicional é por estacas radiciais que é de simples preparo e baixo custo. Essa metodologia consiste em multiplicar partes seccionadas das raízes da planta- 
matriz, que, se colocadas em condições favoráveis, produzem raízes adventícias e emitem brotações que formarão uma planta ou muda. No entanto, essa metodologia apresenta a desvantagem de produzir mudas desuniformes, além da possibilidade de transmissão de patógenos do solo.

Bioestimulante, segundo Castro e Vieira (2001), seria a mistura de dois ou mais reguladores vegetais ou outras substâncias, como aminoácidos, nutrientes e vitaminas, possuindo a capacidade de estimular o desenvolvimento radicial, aumentando a absorção de água e nutrientes pelas raízes, podendo favorecer, também, o equilíbrio hormonal da planta e seu desenvolvimento.

O Promalin $₫$ é um bioestimulante comercial formado por dois reguladores vegetais, um do grupo químico das citocininas (CK) e outro das giberelinas (GA), que atuam no aumento da divisão celular e no alongamento das células, assim como a plasticidade da cutícula (WACHOWICZ; CARVALHO, 2002; VALENT BIOSCIENCES, 2010).

A citocinina pode regular a divisão celular in vivo, atuando no aumento do meristema apical da raiz, que é sua principal fonte. Nesse tecido, a citocinina pode desempenhar papel importante na regulação da proliferação de células iniciais da vascularização da raiz. A giberelina é sintetizada, principalmente no ápice caulinar e nas folhas jovens em desenvolvimento, sendo encontrada também em exsudatos e extratos de raízes, participa da divisão celular e do crescimento da parte aérea (TAIZ; ZEIGER, 2009).

Diversos trabalhos na literatura citam o uso de Promalin ${ }^{\circledR}$ influenciando o desenvolvimento das plantas (EMONGOR et al., 2004; JACYNA; PUCHALA, 2004; RUFATO et al., 2004; KIM et al., 2005; BENNEWITZ et al., 2010), além do florescimento (FUNNELL; MACKAY, 1992).

Assim, este trabalho objetivou verificar o efeito do bioestimulante Promalin ${ }^{\circledR}$, na promoção da brotação, em estacas de raiz de amoreira-preta cv. Brazos.

\section{MATERIAL E MÉTODOS}

O trabalho foi conduzido de janeiro a março de 2010, no Departamento de Produção Vegetal, Setor de Horticultura, pertencente à Faculdade de Ciências Agronômicas, Universidade Estadual Paulista (UNESP), Botucatu-SP, que apresenta as seguintes coordenadas geográficas: latitude $22^{\circ} 55^{\prime} 55^{\prime}$ ' sul, longitude $48^{\circ} 26^{\prime} 22^{\prime \prime}$ oeste e altitude $810 \mathrm{~m}$.

Estacas radiciais de amoreira-preta cv. Brazos foram coletadas da parte superficial do solo $(0-20 \mathrm{~cm})$ de plantas-matrizes de pomar comercial no município de Itatinga (SP). Procedeu-se à seleção e padronização das estacas de acordo com o diâmetro de $10 \mathrm{~mm}$ e comprimento de $150 \mathrm{~mm}$, sendo realizado corte transversal em ambos os lados da estaca.

$\mathrm{O}$ delineamento experimental foi o inteiramente casualizado (DIC), constituído de cinco concentrações de bioestimulante e sete repetições, sendo a unidade experimental constituída de uma bandeja com 10 estacas radiciais. Os tratamentos constaram de cinco concentrações de bioestimulante: $\mathrm{T} 1=0 \mathrm{mg}$ $\mathrm{L}^{-1} ; \mathrm{T} 2=10 \mathrm{mg} \mathrm{L}^{-1} ; \mathrm{T} 3=20 \mathrm{mg} \mathrm{L}^{-1} ; \mathrm{T} 4=40 \mathrm{mg} \mathrm{L}^{-1}$, e T5 $=$ $80 \mathrm{mg} \mathrm{L}^{-1}$. As estacas radiciais foram mergulhadas nessas soluções durante 12 horas. O bioestimulante Promalin ${ }^{\circledR}$ é constituído por $1,8 \%$ de benziladenina (BA), uma citocinina (CK) e 1,8\% de giberelinas (GA), $\mathrm{GA}_{4}+\mathrm{GA}_{7}$, com o objetivo de estimular o crescimento lateral (VALENT BIOSCIENCES, 2010).

As estacas foram colocadas espaçadas cerca de três centímetros umas das outras, em bandejas de polietileno brancas, forradas e cobertas com substrato composto por: casca de arroz carbonizada, fibra de coco e vermiculita (v:v:v), sendo adicionados $100 \mathrm{~g}$ de termofosfato magnesiano (Yoorin Master) para cada $50 \mathrm{~L}$ de substrato. As bandejas foram devidamente colocadas em câmara de nebulização intermitente, com duração de 20 segundos de aspersão, a intervalos de 30 minutos.

Com o auxílio de pulverizador manual, foi realizada pulverização com o fungicida tiofanato

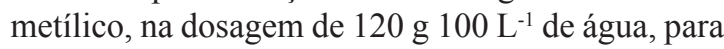
o controle preventivo de patógenos. Além disso, após a emergência das brotações, procedeu-se à pulverização semanal de fertilizante mineral misto Plantafol ${ }^{\circledR}$

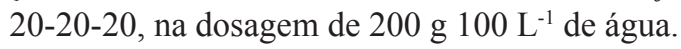

Para a variável evolução da emergência das brotações feita no período de 7 a 49 dias, para os tratamentos com $0 \mathrm{mg} \mathrm{L}^{-1}$ e $10 \mathrm{mg} \mathrm{L}^{-1}$ de bioestimulante, procedeu-se ao estudo de regressão.

Após um período de 75 dias foram avaliadas as seguintes características: número de estacas brotadas (NEB), número de brotos totais por estaca (NBE), comprimento da haste principal (CHP), porcentagem de sobrevivência das brotações (\%SOB) e análise de carboidratos solúveis.

Para a determinação da quantidade de açúcares solúveis, procedeu-se à secagem das estacas de raízes retiradas do campo, antes e após o tratamento com diferentes concentrações de bioestimulante. Posteriormente, as amostras foram levadas ao laboratório e divididas em quatro repetições de $100 \mathrm{mg}$ de material seco e moído. Esse material foi colocado em erlenmeyer contendo $50 \mathrm{~mL}$ de água destilada e, em seguida, colocado em banho-maria a $40^{\circ} \mathrm{C}$, por 30 
minutos, com agitação casual. Tal solução foi filtrada em algodão, sendo colocada em balão volumétrico e completado seu volume até $100 \mathrm{~mL}$. Esta solução foi denominada de amostra. A metodologia empregada para a determinação de açúcares solúveis foi a descrita por Dubois et al. (1956), utilizando-se de $0,5 \mathrm{~mL}$ de amostra, $0,5 \mathrm{~mL}$ de fenol e 2,5 mL de ácido sulfúrico. As leituras foram realizadas em espectrofotômetro no comprimento de onda de $490 \mathrm{~nm}$.

Os dados obtidos em todas as avaliações foram submetidos à análise de variância (teste F), e as médias, comparadas pelo teste de Tukey, a 5\% de significância; posteriormente, foram realizados estudos de regressão, conforme Banzatto e Kronka (2006), adotando-se o programa computacional Sisvar 5.3 (FERREIRA, 2008; 2010).

\section{RESULTADOS E DISCUSSÃO}

Observou-se que as estacas de amoreira-preta iniciaram a emergência das brotações em, aproximadamente, 7 dias após o plantio das estacas (DAP). Após a emergência das primeiras brotações, houve evolução gradativa da emergência das brotações em estacas de raiz de amoreira-preta, refletida na existência de uma correspondência funcional, apresentada pela equação de regressão (Figura 1). Conforme a curva de crescimento, observa-se a evolução da emergência das brotações ao longo do tempo, onde as estacas não tratadas com o bioestimulante (testemunha) iniciaram a emergência das brotações em torno de 5 dias, enquanto na concentração de $10 \mathrm{mg}$ $\mathrm{L}^{-1}$ de Promalin ${ }^{\circledR}$ a emergência das brotações se iniciou em torno de 21 dias. Nos demais tratamentos estudados, ocorreram poucas ou nenhuma formação de brotações.

De modo geral, verificou-se que, para todas as características avaliadas, houve decréscimo dos valores com o aumento da concentração de bioestimulante aplicada às estacas de raízes de amoreirapreta (Tabela 1), tendo a testemunha $\left(0 \mathrm{mg} \mathrm{L}^{-1}\right)$ apresentado resultados estatisticamente superiores às demais concentrações de bioestimulante. Este fato, possivelmente, é explicado devido aos níveis endógenos de metabólitos e hormônios vegetais e/ou associação entre eles, sobretudo citocininas poderiam estar em níveis satisfatórios para o desenvolvimento de brotações e raízes, que unido à aplicação de bioestimulante pode ter causado efeito fitotóxico.

Zuffellato-Ribas e Rodrigues (2001) revelaram a influência da época do ano no sucesso da propagação por estacas, estando intimamente relacionado com os níveis endógenos de promotores e inibidores de crescimento. Geralmente, níveis altos de auxinas e baixos de citocininas podem favorecer a formação de raízes adventícias, e níveis baixos de auxinas e altos de citocininas podem favorecer a formação de brotos adventícios. Estacas de espécies com altos níveis endógenos de citocininas têm mais dificuldade para enraizar do que aquelas com baixos níveis (HARTMANN et al., 2002).

Com relação ao número de estacas brotadas (NEB), número de brotos por estaca (NBE), comprimento da haste principal (CHP) e porcentagem de sobrevivência das brotações (\%SOB), houve diferença entre a testemunha $\left(0 \mathrm{mg} \mathrm{L}^{-1}\right)$, apresentando resultados superiores aos demais tratamentos. A partir da concentração de $10 \mathrm{mg} \mathrm{L}^{-1}$ do bioestimulante, verificou-se redução gradativa desses valores, conforme Tabela 1.

Estudando a multiplicação in vitro de amoreira-preta, Villa et al. (2006) constataram que a multiplicação de brotos ocorreu apenas nos meios de cultura que continham cinetina. Augusto et al. (2006) testaram o enraizamento de amoreira-preta cv. Brazos ex vitro de microestacas multiplicadas com diferentes citocininas, BAP, cinetina, zeatina e 2-isopenteniladenina nas concentrações de 5 e 10 $\mu \mathrm{M}$, constatando que as taxas de enraizamento e sobrevivência foram de $100 \%$.

Citocininas e gibelinas em baixas concentrações promovem o crescimento e o desenvolvimento vegetativo de diferentes espécies, devendo, entretanto, estudar concentrações mais baixas desses reguladores vegetais, além de outros fatores que possam influenciar na propagação da espécie, como a cultivar, a época de coleta de material, a parte da planta utilizada e o conteúdo endógeno de diversas substâncias, como os compostos fenólicos, os carboidratos, dentre outras. Ochoa et al. (2004) mencionaram que a temperatura não afetou significativamente a mobilização de carboidratos, porém o nível inicial de amido e a redução final dos carboidratos estavam relacionados com o enraizamento.

Conforme a Figura 2, os teores de açúcares solúveis variaram de 12,26 a 84,44 $\mathrm{mg} \mathrm{g}^{-1}$ de massa seca nas estacas de raízes antes e após o tratamento com diferentes concentrações de bioestimulante. Observa-se que, durante o processo da brotação, houve acúmulo de açúcares nas estacas radiciais, possivelmente devido à liberação de carboidratos estruturais e formação de açúcares simples, durante o processo de formação da parte vegetativa. Esse acúmulo observado nos tratamentos com as concentrações de 20 e $40 \mathrm{mg} \mathrm{L}^{-1}$ de Promalin ${ }^{\circledR}$ pode estar relacionado com a não utilização desses açúcares, ou seja, com a baixa brotação observada nos dois tratamentos. A exceção foi o tratamento com a maior 
concentração do bioestimulante ( $\left.80 \mathrm{mg} \mathrm{L}^{-1}\right)$, que não se alterou durante esse processo.

A concentração de $0 \mathrm{mg} \mathrm{L}^{-1}$ de PromalinÒ (testemunha) apresentou formação de poucas raízes e acúmulo médio de 51,71 mg glicose $\mathrm{g}^{-1}$ de massa seca, além da formação da parte aérea, com acúmulo médio de 48,30 mg glicose $\mathrm{g}^{-1}$ de massa seca. Entretanto, na concentração de $10 \mathrm{mg} \mathrm{L}^{-1}$, houve acúmulo médio de 54,32 mg glicose $\mathrm{g}^{-1}$ de massa seca, com acúmulo médio da parte aérea de $65,47 \mathrm{mg}$ glicose $\mathrm{g}^{-1}$ de massa seca, sendo somente nas concentrações de 0 e $10 \mathrm{mg} \mathrm{L}^{-1}$ que apresentaram parte aérea para tal determinação.

Reis et al. (2000) revelaram que, embora os carboidratos sejam de grande importância para o enraizamento, servindo como fonte de energia e carbono para a síntese de diversas substâncias essenciais, verificou-se que eles não foram determinantes em promover ou melhorar a capacidade de enraizamento das estacas de Pyrus calleryana.

Outros autores revelaram a importância dos teores de carboidratos na formação, mobilidade e acúmulo de açúcares nas diferentes partes das plantas, dentre eles: Cometti et al. (2004) com a cultura da alface, além de Girardi e Pescador (2010) com Zingiber officinale Roscoe.

Outro fator, que tem de ser considerado, é a influência da época de coleta de material na variação dos teores de açúcares totais. Ferriani et al. (2008), trabalhando com estacas de vassourão-branco (Piptocarpha angustifolia Dusén), constataram variação do teor de açúcares totais durante diferentes épocas, alcançando teores em torno de $300 \mathrm{mg} \mathrm{g}^{-1}$ de tecido (Primavera/2004), $280 \mathrm{mg} \mathrm{g}^{-1}$ de tecido
(Verão/2005), $580 \mathrm{mg} \mathrm{g}^{-1}$ de tecido (Outono/2005) e $350 \mathrm{mg} \mathrm{g}^{-1}$ de tecido (Inverno/2005).

Ono et al. (1995), trabalhando com estacas caulinares de kiwi (Actinidia chinensis Planch.) variedade Abbott, verificaram que o inverno e o outono foram as melhores épocas de coleta de ramos para a produção das estacas caulinares, sendo que o alto teor de açúcares redutores e totais beneficiou a maior porcentagem de enraizamento (aproximadamente, 23 e 36\%, respectivamente). Ohland et al. (2009) verificaram que houve maior enraizamento para as estacas apicais de figueira coletadas no mês de junho, com tratamento basal de $2.000 \mathrm{mg} \mathrm{L}^{-1}$ de IBA, proporcionando $70 \%$ de enraizamento.

Avaliando o efeito da sazonalidade nos teores de açúcares de dois clones de eucalipto, Torres (2003) observou aumento de $9,10 \%$ no verão em relação ao inverno. $\mathrm{O}$ ganho em açúcares propiciou incremento de $138 \%$ e $143 \%$ em biomassa, e em termos de sobrevivência ocorreram ganhos de $2,60 \%$ e 1,69\%, e, em termos de número de estacas produzidas/cepa, os ganhos foram de $212,80 \%$ e $145,48 \%$ para os dois clones de eucalipto, respectivamente.

Entretanto, Bortolini et al. (2008) mencionaram que, para estacas de Tibouchina sellowiana (Cham.) Cogn, não houve relação positiva entre as altas concentrações de carboidratos e proteínas nas diferentes estações do ano com relação ao enraizamento. Análises bioquímicas feitas nas estacas revelaram que as maiores concentrações de açúcares totais foram obtidas no inverno $\left(83,21 \mathrm{mg} \mathrm{g}^{-1}\right.$ de tecido) e no outono $\left(72,79 \mathrm{mg} \mathrm{g}^{-1}\right)$, recomendando a aplicação de $3.000 \mathrm{mg} \mathrm{L}^{-1}$ IBA na forma líquida ou em talco para estacas coletadas na primavera.

TABELA 1- Médias do número de estacas brotadas (NEB), número de brotos por estaca (NBE), comprimento da haste principal (CHP, em cm) e porcentagem de sobrevivência das brotações (\%SOB) em estacas radiciais de amoreira-preta tratadas com diferentes concentrações de bioestimulante Promalin ${ }^{\circledR}{ }^{(1)}$

\begin{tabular}{ccccc}
\hline Concentrações $\left(\mathrm{mg} \mathrm{L}^{-1}\right)$ & NEB & NBE & CHP & $\%$ SOB \\
\hline 0 & $9,71 \mathrm{a}$ & $2,28 \mathrm{a}$ & $23,71 \mathrm{a}$ & $64,76 \mathrm{a}$ \\
10 & $2,00 \mathrm{~b}$ & $1,36 \mathrm{~b}$ & $5,71 \mathrm{~b}$ & $13,33 \mathrm{~b}$ \\
20 & $0,42 \mathrm{c}$ & $1,00 \mathrm{~b}$ & $0,57 \mathrm{c}$ & $2,85 \mathrm{c}$ \\
40 & $0,00 \mathrm{c}$ & $0,00 \mathrm{~b}$ & $0,00 \mathrm{c}$ & $0,95 \mathrm{c}$ \\
80 & $0,14 \mathrm{c}$ & $1,00 \mathrm{~b}$ & $0,00 \mathrm{c}$ & $0,00 \mathrm{c}$ \\
\hline $\mathrm{CV}(\%)$ & 26,94 & 53,20 & 40,56 & 26,93 \\
\hline
\end{tabular}

(1) Médias seguidas de mesma letra nas colunas não diferem significativamente entre si, pelo teste de Tukey, a $5 \%$ de probabilidade. 


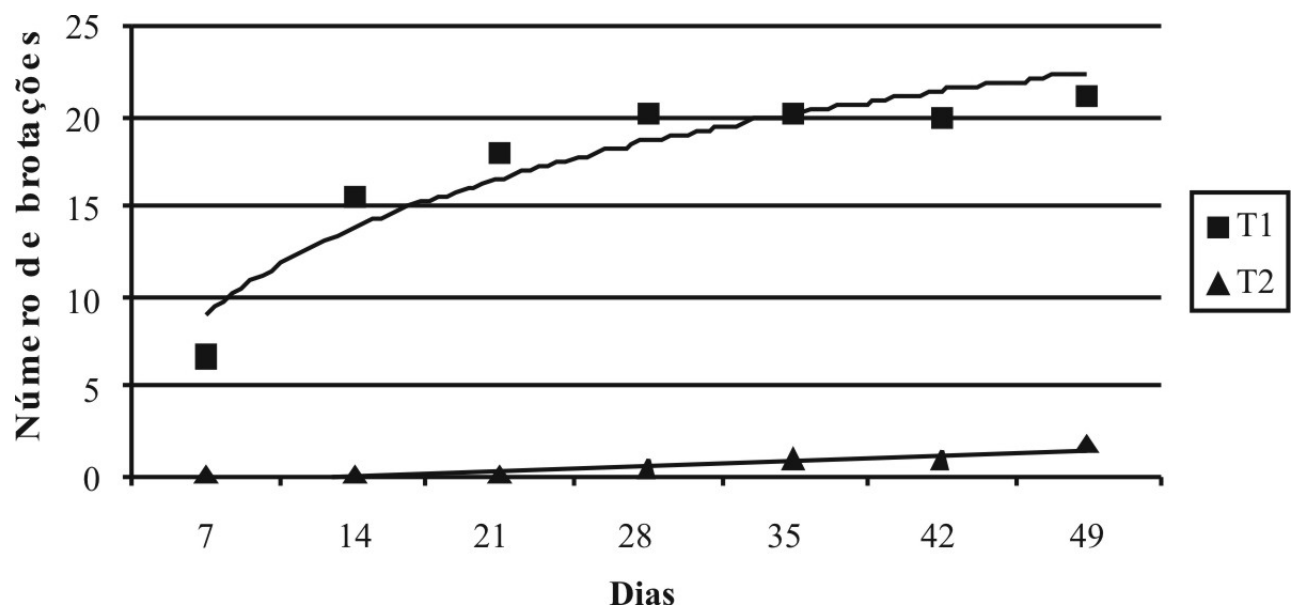

FIGURA 1- Evolução da emergência das brotações em estacas radiciais de amoreira-preta tratadas com

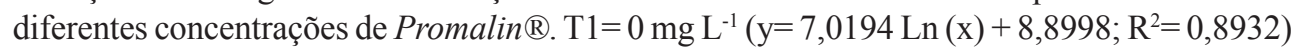
e $\mathrm{T} 2=10 \mathrm{mg} \mathrm{L}^{-1}\left(\mathrm{y}=0,2593 \mathrm{x}-0,5286 ; \mathrm{R}^{2}=0,8161\right)$.

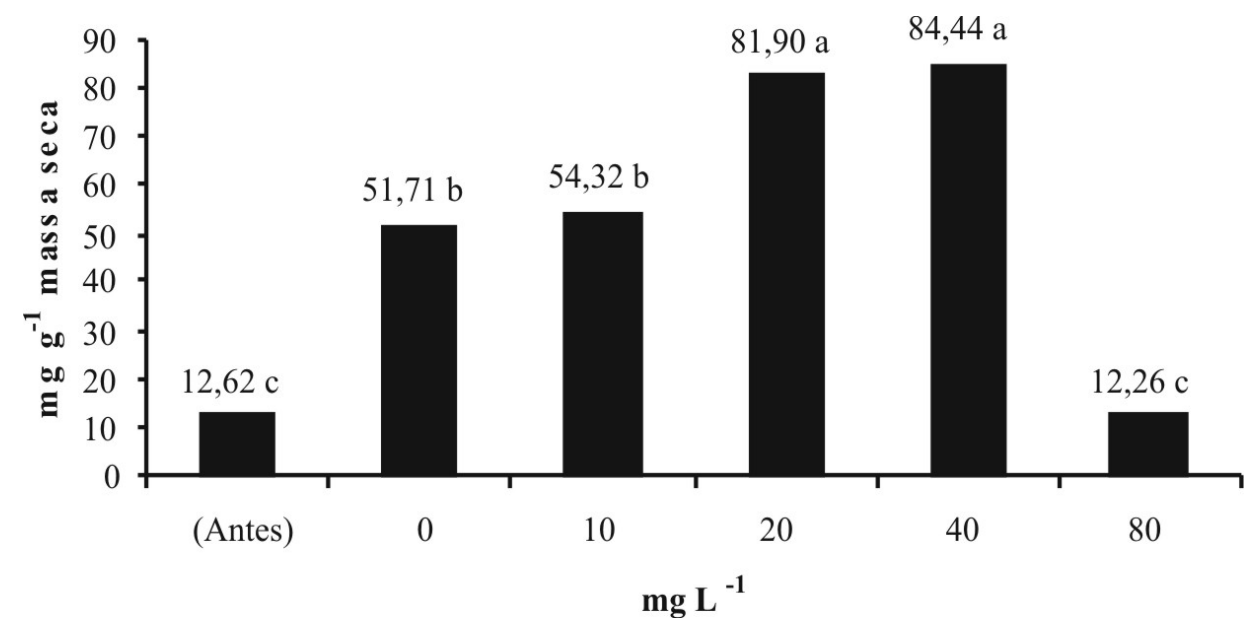

FIGURA 2- Teor de açúcares solúveis em estacas de raízes de amoreira-preta tratadas com diferentes concentrações de bioestimulante Promalin ${ }^{\circledR}$, antes e após o processo de brotação. Médias seguidas por letras distintas diferem entre si, pelo teste de Tukey, a $5 \%$ de probabilidade. $\mathrm{CV}=5,90 \%$.

\section{CONCLUSÃO}

A aplicação de bioestimulante Promalin ${ }^{\circledR}$ nas concentrações estudadas inibi o desenvolvimento de brotações em estacas radiciais de amoreira-preta e altera as características de desenvolvimento dessas brotações.

\section{AGRADECIMENTOS}

À CAPES, ao Departamento de Horticultura - UNESP (FCA) e à Fazenda Santa Terezinha do Rio Bonito.

\section{REFERÊNCIAS}

AUGUSTO, C. S. S.; BIASI, L. A.; TELLES, C. A. Enraizamento e aclimatação de plantas micropropagadas de amoreira-preta cv. Brazos. Revista Brasileira de Fruticultura, Jaboticabal, v. 28, n. 3, p. 473-476, 2006.

BANZATTO, D. A.; KRONKA, S. do N. Experimentação agrícola. 4. ed. Jaboticabal: Funep, 2006. 237 p.

BORTOLINI, M. F.; ZUFFELLATO-RI- 
BAS, K. C.; KOEHLER, H. S.; CARPANEZZI, A. A.; DESCHAMPS., C.; OLIVEIRA, M. C.; BONA, C.; MAYER, J. L. S. Tibouchina sellowiana (Cham.) Cogn.: Enraizamento, anatomia e análises bioquímicas nas quatro estações do ano. Ciência Florestal, Santa Maria, v. 18, n. 2, p. 159-171, 2008.

CASTRO, P. R. E.; VIEIRA, E. L. Aplicações de reguladores vegetais na agricultura tropical. Guaíba: Agropecuária, 2001. 588 p.

CATI. Distribuição geográfica de área cultivada e número de produtores, 2007/08, São Paulo. Levantamento Censitário das Unidades de Produção Agropecuária do Estado de São Paulo. Disponível em: $<$ http://www.cati.sp.gov.br/projetolupa/mapaculturas/ AmoraPreta.php>. Acesso em: 27 maio 2010.

COMETTI, N.N.; MATIAS, G.C.S.; ZONTA, E.; MARY, W.; FERNANDES, M.S. Compostos nitrogenados e açúcares solúveis em tecidos de alface orgânica, hidropônica e convencional. Horticultura Brasileira, Brasília, v.22, n.4, p.748-753, 2004.

DUBOIS, M.; GILLEWS, K. A.; HAMILTON, J. K.; REBER, P. A.; SMITH, F. Colorimetric method for determination of sugar and related substances. Analytical Chemistry, Washington, v. 28, n. 3, p. 350-356, 1956.

EMONGOR, V.; PULE-MEULENBERG, F.; PHOLE, O. Effect of Promalin in growth and development of Kale. Journal of Agronomy, New York, v. 3, n. 3, p. 208-214, 2004.

FERREIRA, D. F. Sisvar: um programa para análises e ensino de estatística. Revista Científica Symposium, Lavras, v. 6, n. 2, p. 36-41, 2008.

FERREIRA, D. F. Sisvar: versão 5.3. Lavras: UFLA, 2010.

FERRIANI, A. P.; MAYER, J. L. S.; ZUFFELLATO-RIBAS, K. C.; BONA, C.; KOEHLER, H. S.; DESCHAMPS., C.; CARPANEZZI, A. A.; OLIVEIRA, M. C. Estaquia e anatomia de vassourãobranco. Scientia Agraria, Piracicaba, v. 9, n. 2, p. 159-166, 2008.
FUNNELL, K. A.; MACKAY, B. R. Comparative effects of Promalin and $\mathrm{GA}_{3}$ on flowering and development of Zantedeschia 'Galaxy'. Acta Horticulturae, The Hague, n. 292, p.173-179, 1992.

GIRARDI, C.G.; PESCADOR, R. Aclimatação de gengibre (Zingiber officinale Roscoe) e a relação com carboidratos endógenos. Revista Brasileira de Plantas Medicinais, Botucatu, v.12, n.1, p.6272, 2010.

HARTMANN, H. T.; KESTER, D. E.; DAVIES JUNIOR, F. T.; GENEVE, R. L. Plant propagation: principles and pratices. $7^{\text {th }}$ ed. New Jersey: PrenticeHall, 2002. 880 p.

JACYNA, T.; PUCHALA, A. Application of environment friendly Branco promoting substances to advance sweet cherry tree Canopo development in the orchard. Journal of Fruit and Ornamental Plant Research, Skierniewice v. 12, p. 177-182, 2004. Special Edition

KIM, S. K.; KIM, J. T.; JANG, S. W.; LEE, S.C.; LEE, B. H.; LEE, I. J. Exogenous effect of gibberellins and jasmonate on tuber enlargement of Dioscorea opposita. Agronomy Research, Saku, v. 3, n. 1, p. 39-44, 2005.

OCHOA, J.; BAÑÓN, S.; FERNÁNDEZ, J. A.; FRANCO, J. A.;MARTÍNEZ-SÁNCHEZ, J. J. Rooting medium temperature and carbohydrates affected oleander rooting. Acta Horticulturae, The Hague, n. 659, p.239-242, 2004.

OHLAND, T. et al. Enraizamento de estacas apicais de figueira "Roxo de Valinhos" em função de época de coleta e AIB. Ciência Agrotecnia, Lavras, v. 33 , n. 1, p. 74-78, 2009.

ONO, E. O.; RODRIGUES, J. D.; PINHO, S. Z. Enraizamento de estacas caulinares de kiwi (Actinidia chinensis Planch. Vc Abbott) tratadas com auxinas e boro. Ciencia Agricola, Piracicaba, v. 52, n. 3, p. 462-468, 1995.

RASEIRA, M. C. B. A pesquisa com amora-preta no Brasil. In: SIMPÓSIO NACIONAL dO MORANGO, 2 E ENCONTRO DE PEQUENAS FRUTAS E FRUTAS NATIVAS, 1., 2004, Pelotas. Palestras... Pelotas: Embrapa Clima Temperado, 2004. p. 119123. (Documentos, 124). 
REIS, J. M. R. et al. Efeito do estiolamento e do ácido indolbutírico no enraizamento de estacas do portaenxerto Pyrus calleryana Dcne. Ciência Agrotecnia, Lavras, v.24, n.4, p.931-938, 2000.

RUFATO, L.; DE ROSSI, A.; FARIA, J. L. C. Uso de promalina e incisão anelar no incremento do crescimento vegetativo de ramos laterais em pessegueiro (Prunus pérsica (L.) Batsch) conduzidos em axis colunar. Revista Brasileira de Agrociência, Pelotas, v. 10, n. 1, p. 117-122, 2004.

TAIZ, L.; ZEIGER, E. Fisiologia vegetal. 3. ed. Porto Alegre: Artmed, 2009. 819 p.

TORRES, A. G. M. Relação entre sazonalidade, desrama e carboidratos no crescimento de eucalipto na propagação vegetativa por miniestaquia. 2003. 65 f. Dissertação (Mestre em Recursos Florestais, com opção em Manejo de Florestas de Produção) - Escola Superior de Agricultura Luiz de Queiroz, Piracicaba, 2003.
VALENT BIOSCIENCES. Disponivel em:

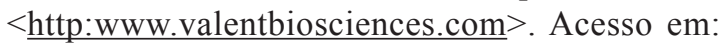
19 ago. 2010.

VILLA, F.; PASQUAL, M.; PIO, L. A. S.; TEODORO, G. S.; MIYATA, L. Y. Multiplicação in vitro de amoreira-preta "Cherokee": efeito de meios de cultura, cinetina e GA 3 Revista Ceres, Viçosa, MG, v. 1, n. 1, p.357-362, 2006.

WACHOWICZ, C. M.; CARVALHO, R. I. N. Fisiologia vegetal: produção e pós-colheita. Curitiba: Chanpagnat, 2002. 424p.

ZUFFELLATO-RIBAS, C. K.; RODRIGUES, D. J. Estaquia: uma abordagem dos principais aspectos fisiológicos. Curitiba: EUFPR, 2001. 